\title{
Social media use for public health promotion in the Gulf Cooperation Council
}

\author{
An overview
}

Sana A. AlSadrah, BSMLS, MPH.

\begin{abstract}

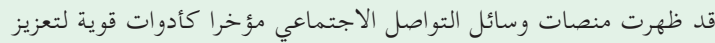

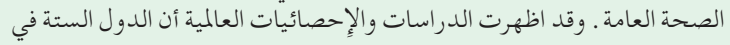

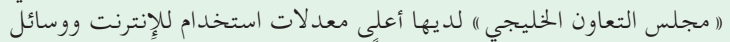

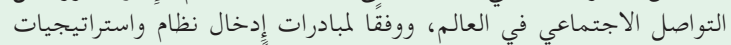

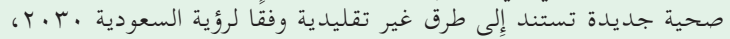

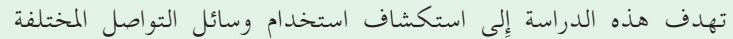

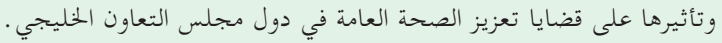

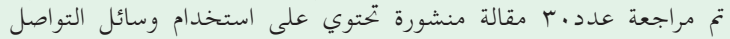

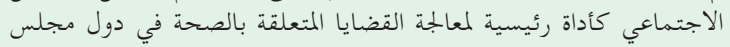

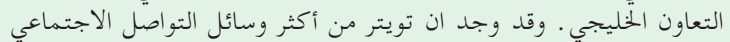

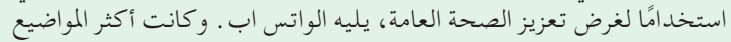

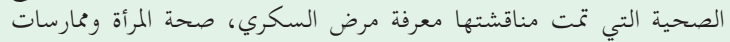

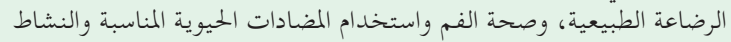

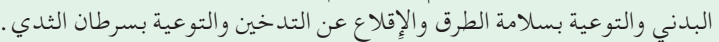

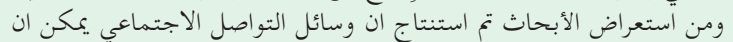

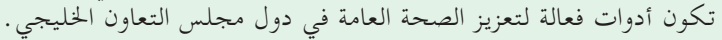

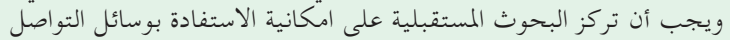

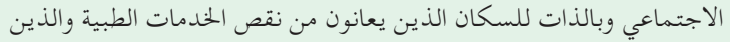

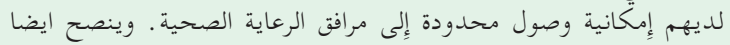

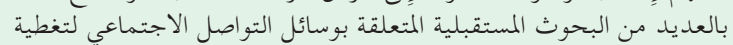

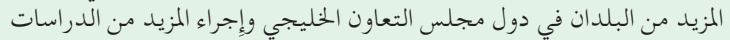

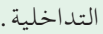

Social media platforms (SMPs) have emerged as powerful tools for public health promotion. As the 6 countries of the Gulf Cooperation Council (GCC) have the highest internet and social media usage rates in the world, and according to the initiatives for the introduction of a new health system and strategies based on non-traditional methods according to the Saudi Vision 2030, this review aimed to investigate different SMPs use and impact on public health promotion in the GCC countries. Accumulating evidence indicated that diabetes knowledge, women's health, breast-feeding practices, oral health, appropriate antibiotic use, physical activity, road safety awareness, quitting smoking, and breast cancer awareness, were the most common specified topics. Future research should focus on populations that are medically underserved and who have no or limited access to health-care facilities. Also, future research, in particular, the intervention type, is required to cover more countries in the GCC.

Keywords: social media, health promotion, Gulf Cooperation Council, Saudi Arabia, Facebook, Twitter, WhatsApp

Saudi Med J 2021; Vol. 42 (1): 9-20 doi: 10.15537/smj.2021.1.25470

From the Department of Preventive Medicine, Governmental Hospital, Khobar Health Centers, Ministry of Health, AlKhobar, Kingdom of Saudi Arabia.

Address correspondence and reprint request to: Dr. Sana A. AlSadrah, Department of Preventive Medicine, Governmental Hospital, Khobar Health Centers, Ministry of Health, AlKhobar, Kingdom of Saudi Arabia.E-mail: sana12345.uk@yahoo.com

ORCID ID: http://orcid.org/0000-0002-1254-3542
$\mathrm{I}$ n 2019, it was estimated that there were 2.7 billion social media users worldwide, and this figure is speculated to increase to 3 billion by $2021 .^{1}$ In light of these figures, it is becoming difficult to ignore the potential role that various online social media platforms (SMPs) could play as powerful channels for public health promotion. ${ }^{2}$ As public media campaigns can be expensive with inconsistent and difficult-to-assess outcomes, ${ }^{3}$ different online SMPs, including Twitter, Facebook, YouTube, Snapchat, and Instagram, have emerged as frequently utilized platforms addressing health-related issues. ${ }^{4-7}$ In several geographic places, such as the "Gulf Cooperation Council (GCC)" countries, namely, "Saudi Arabia, United Arab Emirates, Kuwait, Oman, Qatar, and Bahrain", where over 54 million people live according to population estimates, ${ }^{8}$ these platforms have become increasingly common. The present online data show that the most used SMPs in 
the GCC are "Facebook, Twitter, and YouTube" (http:// gs.statcounter.com). The high socioeconomic status of these countries and the efficient networking and communication infrastructure have enabled the spread of such platforms in the specified area. ${ }^{4}$

Consistent with the steady growth displayed in several sectors, including the health-care sector, several GCC countries have committed to the Saudi Vision 2030, which aims to enhance the efficiency and quality of the preventive and therapeutic health-care services by streamlining processes and diversifying communication channels.' In this sense, a growing focus on patient engagement by reducing the barriers to effective communication through online SMPs is required. ${ }^{10}$

The literature on SMPs' role as a tool for public health communication is still lacking. Accumulating evidence shows that targeted users prefer to engage in interactive multidirectional conversations about health information rather than one-way communication. ${ }^{11,12}$ Social media could be valuable in documenting the range of health-related behaviors, promoting awareness of health-protective strategies, and providing interventions for public health issues. ${ }^{3,4,7}$ However, the quality of health information provided via diverse social media tools can vary, raising some concerns about the putative hazards to social media users who might be exposed to unopposed viewpoints that contradict medical science and public health recommendations. ${ }^{13-15}$

Although previous publications have evaluated the usage of different SMPs in public health, the information collected about the use of different SMPs for health promotion among the GCC countries as a review article is insufficient. In this sense, this study aimed to explore the online peer-reviewed literature to discern the different SMPs use for health promotion among the GCC populations and also to recognize some concerns that need improvement for future health promotion-related research.

The author consulted a software specialist to determine the common terms used to describe SMPs, and then performed a computerized search of Google Scholar, Scopus, Medline (via PubMed), and Web of Science databases up to June 2019, using the following keywords: "Social media OR Social web OR Social software OR Social network OR Web2 OR Web 2.0 OR telemedicine 2 OR SMP OR Facebook OR Twitter OR

Disclosure. Authors have no conflict of interests, and the work was not supported or funded by any drug company.
Snapchat OR WhatsApp" AND "Health OR Health promotion" AND "Gulf region OR GCC” OR "Saudi Arabia" OR "United Arab Emirates" OR "Kuwait" OR "Oman" OR "Qatar" OR "Bahrain". The reference list of relevant studies was examined, and some related studies were included. ${ }^{16,17}$ The findings of the retrieved studies were used to synthesize recommendations concerning the use of SMP for health promotion in the Gulf region.

Retrieved articles. The initial search after removal of the duplicates retrieved 1960 unique citations. After title/abstract screening, 85 citations were entered into the full-text screening phase. Fifty-five articles were excluded: 35 articles due to irrelevant content, 18 related articles, but not matching one or more of the eligibility criteria as well as 2 review articles. Finally, 30 studies were enrolled in the current work. ${ }^{4,16-44}$ Figure 1 summarizes the flow of the included literature during the searching strategy.

Publication dates and study locations. As noted in Table 1, the earliest item is from $2013,{ }^{18}$ with more frequent publications in the subsequent years. The "country of origin" revealed that the SMP uses for public health promotion in the GCC countries originated remarkably in Saudi Arabia (23/30; 76.7\%). ${ }^{18-26,28,29,31-36,38-40,42-44}$

Almost all the included studies were published as original research $(26 / 30 ; 86.7 \%),{ }^{4,19-36,38-44}$ and only 2 studies were conference proceedings (2/30; $6.7 \%) .{ }^{16,18}$ A qualitative (descriptive in nature) crosssectional study design of the reviewed items using questionnaires or focus groups was predominant (23/30; $76.7 \%), 4,16,18,19-34,36,38,39,44$ with few interventional studies $(3 / 30 ; 10 \%) .{ }^{35,40,42}$ The specified outcomes of each included study are summarized in Table 1.

Social media platforms. Of the SMPs used, Twitter was the most commonly used SMP; applied in 11 of the 30 articles $(36.7 \%),{ }^{4,20-22,25,26,29,32,34,36,38}$ followed by WhatsApp which included in 7 of the 30 articles $(23.3 \%)^{29,33-35,37,38,40}$ Other popular SMPs included Facebook $\quad(\mathrm{n}=5 ; \quad 20 \%),{ }^{17,27,29,32,34}$ Instagram $\quad(\mathrm{n}=7$; $23.3 \%),{ }^{16,17,29,31-33,37}$ and Snapchat $(\mathrm{n}=3 ; 10 \%) .{ }^{29,32,42}$ Interestingly, many studies applied multiple SMPs in the work methodology (Table 1). 4,17,18,26,29,32-34,37,38,44

Target populations. Most studies ( $\mathrm{n}=14 ; 46.7 \%)$ focused on the general population within the GCC countries. $4,16,17,20,23,26,28,29,33,34,36,40-42$ On the other hand, others enrolled participants with specified medical entities/risk factors such as smokers, ${ }^{38}$ patients with diabetes, ${ }^{18,24,27,30,43}$ and obese children. ${ }^{37}$ Few studies $(\mathrm{n}=3 ; 10 \%)$ focused on healthcare professionals, ${ }^{25,32,44}$ and other studies $(\mathrm{n}=6 ; 20 \%)^{4,16,20,27,29,36}$ focused on the 


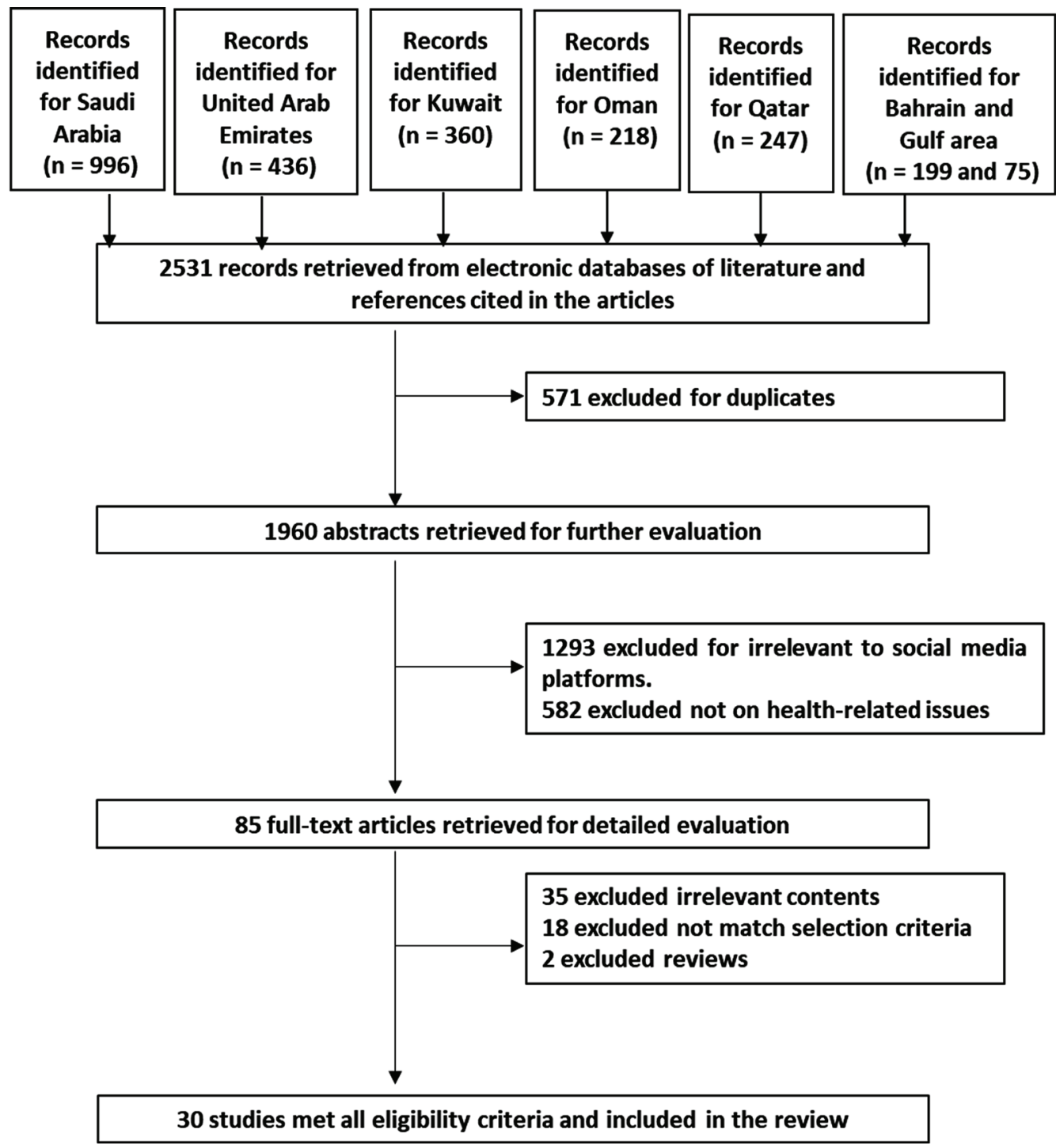

Figure 1 - Flow shart of the included literature during the search stategy.

analysis of public health promotion posts and tweets (Table 1).

Health issues. Of the health issues targeted in the enrolled studies, diabetes-related issues were by far the most highly outlined $(6 / 30 ; 20.0 \%) .^{18,24,27,30,40,43}$ Other health issues were women's health $(2 / 30 ; 6.7 \%)^{20,22}$ and oral health promotion $(2 / 30 ; 6.7 \%)^{23,26}$ healthcare delivery and healthcare professional promotion $(5 / 30$; $16.6 \%),{ }^{25,32-34,44}$ physical activity adherence (3/30; $10.0 \%),{ }^{17,31,37}$ and breast-feeding $(2 / 30 ; 6.7 \%) .{ }^{21,42}$ Less frequently mentioned areas (namely, each represents $1 / 30 ; 3.3 \%)$, included antibiotic awareness, ${ }^{4}$ online medication seeking behavior, ${ }^{29}$ smoking relapse prevention, ${ }^{38}$ resuscitations, ${ }^{39}$ road safety, ${ }^{36}$ breast cancer awareness, ${ }^{42}$ and organ donation and brain death awareness. ${ }^{28}$

Efficacy of SMPs in public health promotion. Awareness to the general population. Overall, the patients/participants expressed a high acceptance of receiving public health promotion messages through SMPs. Mainly, over two-thirds of the study participants were seeking online information about health-related issues. Followers of social media accounts that spread related messages showed better awareness of a range of conditions such as women's health and breast-feeding. 
Table 1 - Summary of the survey studies on social media use in the GCC countries.

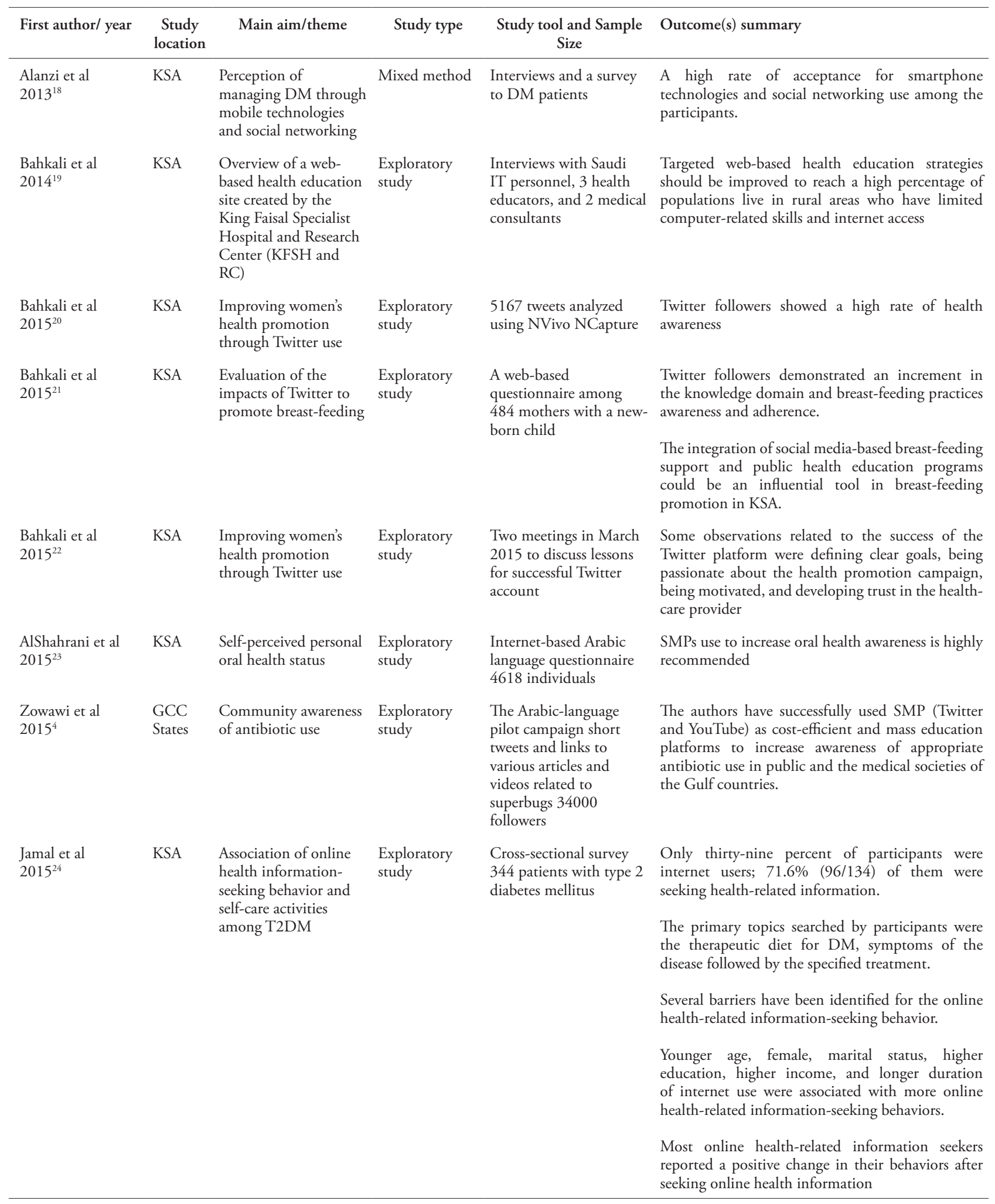


Table 1 - Summary of the survey studies on social media use in the GCC countries (continued).

\begin{tabular}{|c|c|c|c|c|c|}
\hline $\begin{array}{l}\text { Almaiman et al } \\
2015^{25}\end{array}$ & KSA & $\begin{array}{l}\text { Using social media } \\
\text { among health-care } \\
\text { professionals }\end{array}$ & $\begin{array}{l}\text { Exploratory } \\
\text { study (web- } \\
\text { based survey) }\end{array}$ & $\begin{array}{l}\text { Cross-sectional Twitter- } \\
\text { based survey to } 253 \\
\text { physicians }\end{array}$ & $\begin{array}{l}\text { The majority of the enrolled physicians reported, } \\
\text { Twitter had a significant impact on enhancing their } \\
\text { medical knowledge and in improving their clinical } \\
\text { practice. }\end{array}$ \\
\hline
\end{tabular}

The participants depicted their preference for social media health accounts that focus on women's health, non-communicable disease, and psychotherapy.

The need for additional work on designing and implementing a national SMP based educational outreach program to provide evidence-based healthcare information and improve health-care providers' knowledge and skills was recommended.

$\begin{array}{llll}\begin{array}{l}\text { Mejova et al } \\ 2015^{16}\end{array} \quad \text { Qatar } & \begin{array}{l}\text { Assessment of the } \\ \text { Dietary Habits of the } \\ \text { Qatar population }\end{array} & \begin{array}{l}\text { Exploratory } \\ \text { study }\end{array} & \begin{array}{l}\text { Analysis of Instagram } \\ \text { posts }\end{array}\end{array}$

Analysis of Instagram posts revealed its potential as a source for the native and expat populations study, in particular, their dietary and health activity. It revealed that social media has limitations in precisely reflecting the expats, being drastically under-represented.

$\begin{array}{lllll}\begin{array}{l}\text { Almaiman et al } \\ 2016^{26}\end{array} \quad \text { KSA } & \begin{array}{l}\text { Oral health promotion } \\ \text { using social media } \\ \text { platforms }\end{array} & \begin{array}{l}\text { Exploratory } \\ \text { study }\end{array} & \begin{array}{l}\text { Cross-sectional web- } \\ \text { based (Twitter) survey to } \\ 2652 \text { respondents }\end{array}\end{array}$

More than 2/3 of the participants reported searching using social media study 2652 respondents the Arabic online oral health-related information (OHRI). Otherwise, nearly forty percent of the enrolled individuals reported no preference for using a specific SMP.

It is recommended to support the content of SMP with trusted and high-quality online OHRI resources to raise public awareness

AlQarni et al

Arabic Facebook (FB) content Exploratory speaking analysis to diabetes- study

Retrospective qualitative $\mathrm{FB}$ content analysis of world related groups

6107 posts related to DM

The retrospective qualitative FB content analysis has shown that the female gender was predominant users.

Most of the posts focus on sharing personal experiences, raising awareness, providing spiritual support, sharing the latest research, and providing education on DM.

Future research considers health information sharing and designing appropriate interventions to improve social media power in promoting public health is highly recommended.

Hajjar et al $2016^{28}$

KSA

The knowledge, attitudes, and beliefs of organ donation and brain death among social media users living in Saudi Arabia.

Exploratory study

Web-based questionnaire to 913 participants

Most study participants had sufficient information about organ donation versus brain death.

Some participants showed positive attitudes toward organ donation.

SMP showed a significant influence on organ donation and brain death knowledge.

Approximately 68.3\% (3311/4847) were seeking the online medication-related information frequently.

of Saudi online medication seeking behavior via a webbased survey with Twitter participants
Exploratory Retrospective analysis study of 445 tweets related to schizophrenia
Approximately $83.5 \%$ of SMP users were females.

Most respondents used in decreasing order Google (63.6\%), Twitter (28.7\%), Snap chat (21\%), WhatsApp (13.8\%), Instagram (11.4\%), Facebook $(5.5 \%)$, and YouTube $(1.3 \%)$ to access online medication-related information.

Saudi population was active users for the internet and different SMPs to get data about medications. 
Table 1 - Summary of the survey studies on social media use in the GCC countries (continued).

\begin{tabular}{|c|c|c|c|c|c|}
\hline $\begin{array}{l}\text { Alanzi et al } \\
2016^{30}\end{array}$ & GCC & $\begin{array}{l}\text { Design and usability } \\
\text { evaluation of social, } \\
\text { mobile diabetes } \\
\text { management system in } \\
\text { the Gulf Region }\end{array}$ & Usability study & $\begin{array}{l}\text { Questionnaire for User } \\
\text { Interaction Satisfaction } \\
\text { to } 33 \text { users with DM }\end{array}$ & $\begin{array}{l}\text { A higher usability rating in Saudi patients with } \\
\text { T2DM for Saudi Arabia Networking for Aiding } \\
\text { Diabetes (SANAD) health system } \\
\text { The wide deployment of the specified health system } \\
\text { in the Gulf region supported by the wide use of } \\
\text { mobile phones and social networking media, was } \\
\text { recommended }\end{array}$ \\
\hline $\begin{array}{l}\text { Al-Eisa et al } \\
2016^{31}\end{array}$ & KSA & $\begin{array}{l}\text { Effect of motivation } \\
\text { by Instagram on } \\
\text { adherence to physical } \\
\text { activity among female } \\
\text { college students }\end{array}$ & $\begin{array}{l}\text { quasi- } \\
\text { experimental } \\
\text { study }\end{array}$ & $\begin{array}{l}\text { EMI-2: a questionnaire } \\
\text { that measures the } \\
\text { motivation to engage in } \\
\text { physical activity, then } \\
\text { divided into Instagram } \\
\text { and control groups }\end{array}$ & $\begin{array}{l}\text { The intervention-group showed about } 17 \% \text { more } \\
\text { adherence to the activity program versus the } \\
\text { controls } \\
\text { It is concluded that the use of Instagram with the } \\
\text { home exercise program as a motivational modality } \\
\text { could be attractive and effective to reinforce } \\
\text { adherence and maintain an adequate physical } \\
\text { activity level }\end{array}$ \\
\hline $\begin{array}{l}\text { Alsobayel et al } \\
2016^{32}\end{array}$ & KSA & $\begin{array}{l}\text { Use of social media } \\
\text { for professional } \\
\text { development by health } \\
\text { care professionals }\end{array}$ & $\begin{array}{l}\text { Exploratory } \\
\text { study }\end{array}$ & $\begin{array}{l}\text { Cross-sectional web- } \\
\text { based survey to } 231 \\
\text { health-care professionals } \\
\text { using different types of } \\
\text { SMP }\end{array}$ & $\begin{array}{l}\text { Nearly } 70.6 \% \text { of the participants used SMP for } \\
\text { their professional development } \\
\text { The most frequently used SMPs were Twitter, } \\
\text { YouTube, Instagram, Facebook, Snapchat, and } \\
\text { LinkedIn, in descending order } \\
\text { It is concluded that social media were perceived as } \\
\text { being most useful for professional development in } \\
\text { terms of their impact on the domains of knowledge } \\
\text { and problem-solving and least helpful for clinical } \\
\text { skills competency } \\
\text { Also, Twitter was perceived as the most suitable type } \\
\text { of social media for all listed domains }\end{array}$ \\
\hline $\begin{array}{l}\text { Alshammari et al } \\
2017^{33}\end{array}$ & KSA & $\begin{array}{l}\text { Use of social media in } \\
\text { health education and } \\
\text { health promotion }\end{array}$ & $\begin{array}{l}\text { Exploratory } \\
\text { study }\end{array}$ & $\begin{array}{l}\text { Cross-sectional web- } \\
\text { based survey }\end{array}$ & $\begin{array}{l}\text { Instagram, WhatsApp, and SMS were the most } \\
\text { preferred media among people of Saudi Arabia. } \\
\text { There were age and gender differences. } \\
\text { It was a successful practice to use these SMPs to } \\
\text { send health education-related messages to the target } \\
\text { population }\end{array}$ \\
\hline $\begin{array}{l}\text { Iftikhar et al } \\
2017^{34}\end{array}$ & KSA & $\begin{array}{l}\text { Health-seeking } \\
\text { influence reflected by } \\
\text { online health-related } \\
\text { messages received on } \\
\text { social media }\end{array}$ & $\begin{array}{l}\text { Exploratory } \\
\text { study }\end{array}$ & $\begin{array}{l}\text { A questionnaire } \\
\text { with closed-ended } \\
\text { and multiple-choice } \\
\text { questions to } 442 \text { patients }\end{array}$ & $\begin{array}{l}\text { The authors concluded that most respondents } \\
(89.8 \%, 397 / 442) \text { used WhatsApp, followed by } \\
\text { Facebook (58.6\%, 259/442) and Twitter ( } 42.3 \% \text {, } \\
187 / 442) \text {. Most cases, respondents received health- } \\
\text { related messages from WhatsApp, and about } 42.6 \% \\
\text { (171/401) reported ever stopping treatment as } \\
\text { advised on an SMP. Also, a significant proportion } \\
\text { of WhatsApp users reported that health-related } \\
\text { information received on this platform influenced } \\
\text { decisions regarding their family's health care. } \\
\text { Interestingly, respondents decisions regarding } \\
\text { family health care were more likely to be influenced } \\
\text { when they used two or all } 3 \text { types of platforms } \\
\text { (Facebook, WhatsApp, or Twitter). }\end{array}$ \\
\hline $\begin{array}{l}\text { Hemdi et al } \\
2017^{35}\end{array}$ & KSA & $\begin{array}{l}\text { Effectiveness of a } \\
\text { psychoeducation } \\
\text { intervention delivered } \\
\text { via WhatsApp for } \\
\text { mothers of children } \\
\text { with Autism Spectrum } \\
\text { Disorder }\end{array}$ & $\begin{array}{l}\text { Intervention } \\
\mathrm{RCT}\end{array}$ & $\begin{array}{l}\text { The intervention is } \\
\text { one face-to-face session } \\
\text { ( } 60 \text { min), and } 4 \text { virtual } \\
\text { sessions ( } 30 \text { min } \\
\text { each) delivered using } \\
\text { WhatsApp. The sample } \\
\text { size was } 62 \text { mothers of } \\
\text { children ( } 26-78 \text { months) }\end{array}$ & $\begin{array}{l}\text { Stress and depression, but not anxiety, showed } \\
\text { apparent improvement. } \\
\text { Depression showed a change to nearly clinically } \\
\text { normal levels. }\end{array}$ \\
\hline
\end{tabular}


Table 1 - Summary of the survey studies on social media use in the GCC countries (continued).

\begin{tabular}{|c|c|c|c|c|}
\hline $\begin{array}{l}\text { Albalawi et al } \\
2017^{36}\end{array}$ & KSA & $\begin{array}{l}\text { Exploring the diffusion } \\
\text { of tweets designed to } \\
\text { raise the road safety } \\
\text { agenda }\end{array}$ & $\begin{array}{l}\text { Exploratory } \\
\text { study }\end{array}$ & $\begin{array}{l}70 \text { tweets distributed } \\
\text { into two groups ( } 29 \\
\text { intervention tweets anc } \\
41 \text { additional supporte } \\
\text { tweets) extracted from } \\
\text { the Tweet reach data se }\end{array}$ \\
\hline
\end{tabular}

Fernandez-Luque et Qatar al $2017^{37}$

Onezi et al

$2018^{38}$

KSA

The impact of social media-based support groups on smoking relapse prevention

Hassounah et al $2018^{39}$

Alanzi et al $2018^{40}$

KSA

Implementing 360 degrees Quantified Self for childhood obesity

Clinical Trial

Data were collected from 50 children who had wearable devices and Social media accounts, then analyzed using the $360^{\circ}$ Quantified Self (360QS) method, which allows for capturing insights on the behavioral patterns of children

Exploratory $\quad 473$ smokers participate study in smoking-cessation intervention programs, divided into 3 groups: Twitter $(\mathrm{n}=150)$, and WhatsApp $(\mathrm{n}=150)$, and a control group $(\mathrm{n}=$ 173)

KSA

The quality and educational use of the Arabic language cardiopulmonary resuscitation videos published on YouTube

Exploratory study

283 YouTube videos on resuscitation were assessed for educational usefulness

Interventional The intervention study mobile social working application for improving T2DM knowledge

Alhuwail et al Kuwait

Evaluating hospital websites in Kuwait to improve consumer engagement and access to health information

Exploratory study cohort had educationalmessages using WhatsApp weekly, while the controls received the ordinary care $2018^{41}$

KSA $2018^{42}$
Nine hospital websites were evaluated for Accessibility, Usability, Presence, and Content.
Interventional The intervention group study
Evaluation of the Snap Chat mobile social networking application for breast cancer awareness
The authors identified an indicator of successful diffusion and proposed a new way to measure innovation/imitation coefficients.

A statistical maneuver for tweet adoption evaluation by influential and imitators was developed.

Understanding the health-promoting messages diffusion process in SMP, such as Twitter, is very important for the optimal use of these platforms as a tool for public health promotion.

The authors concluded that the acquired physical activity and food data via wearable sensors, mobile and social media (WhatsApp and Instagram), and integration with physiological data to gain insights about health habits allowed for capturing insights on the behavioral patterns of the participated children, which served as a mechanism to reinforce the education of their mothers via social media.

The authors also reported that human factors, such as sex and cultural acceptability aspects, can affect the implementation of this technology beyond a feasibility study and they recommended that for 360QS technology implementation, careful planning and integration in the health professionals workflow are needed.

Twitter and WhatsApp (as extra-treatment to the official health-care session) users found it easier to quit smoking in the smoking cessation intervention program than individuals who did not participate in these activities.

The study findings support that more social media support groups should be developed to help people to cease smoking after abstinence effectively.

The available YouTube videos were not reliable sources of data on how to perform cardiopulmonary resuscitation for the Arabic speaking population at the time of study conduction.

The authors concluded that the WhatsApp application can be effectively used for enhancing diabetes knowledge, self-efficacy, and awareness among the Saudi population.

The authors concluded that overall, most hospitals in Kuwait have a rudimentary online presence, and their websites require careful reassessment concerning design, content, and user experience. Also, the websites focus primarily on promoting services provided by the hospital rather than engaging and communicating with patients or providing evidence-based information. used the Snap Chat mobile application and received breast cancer awareness information on their mobiles
A significant improvement in breast cancer awareness was found in the intervention group who received awareness about breast cancer through Snap Chat using videos, texts, and pictures. 
Table 1 - Summary of the survey studies on social media use in the GCC countries (continued).

\begin{tabular}{|c|c|c|c|c|c|}
\hline $\begin{array}{l}\text { Alanzi et al } \\
2018^{43}\end{array}$ & KSA & $\begin{array}{l}\text { Evaluation of the } \\
\text { effectiveness of mobile } \\
\text { diabetes management } \\
\text { system with social } \\
\text { networking and } \\
\text { cognitive behavioral } \\
\text { therapy for T2DM. }\end{array}$ & $\begin{array}{l}\text { Randomized } \\
\text { controlled trial }\end{array}$ & $\begin{array}{l}\text { The intervention group } \\
\text { used Saudi Arabia } \\
\text { Networking for Aiding } \\
\text { Diabetes (SANAD) } \\
\text { system and the controls } \\
\text { used the conventional } \\
\text { diabetes therapy }\end{array}$ & $\begin{array}{l}\text { The mean diabetes knowledge score has been } \\
\text { increased after the intervention using Saudi Arabia } \\
\text { Networking for Aiding Diabetes }(12.11 \pm 2.09 \\
\text { versus } 14.56 \pm 1.59) \text {. } \\
\text { Also, the mean self-efficacy score has been increased } \\
(5.17 \pm 0.45 \text { versus } 6.17 \pm 0.39) \text {. } \\
\text { Age, sex, and educational level were not associated } \\
\text { with increased knowledge nor the self-efficacy scores } \\
\text { in each study cohort. }\end{array}$ \\
\hline $\begin{array}{l}\text { Alshakhs et al } \\
2018^{44}\end{array}$ & KSA & $\begin{array}{l}\text { Role of social media in } \\
\text { health-care delivery }\end{array}$ & $\begin{array}{l}\text { Exploratory } \\
\text { study }\end{array}$ & $\begin{array}{l}\text { Web-based survey to } 120 \\
\text { health-care professionals }\end{array}$ & $\begin{array}{l}\text { The authors concluded that } 80 \% \text { of study } \\
\text { participants agreed with the benefits of using social } \\
\text { networks in health-care services and considered } \\
\text { it a suitable tool for patient education and } \\
\text { public health awareness. The rest of participants } \\
\text { believed that there are several risks associated with } \\
\text { the use of social media, such as ethical or legal } \\
\text { challenges, the risk to the patient's health status, or } \\
\text { the breaching of the privacy and confidentiality of } \\
\text { the patient. } \\
\text { The participants were welcome to use SMPs for } \\
\text { professional aims. }\end{array}$ \\
\hline $\begin{array}{l}\text { East-Mediterranean } \\
\text { Regional Office, } \\
\mathrm{WHO}^{17}\end{array}$ & Bahrain & $\begin{array}{l}\text { The promotion of } \\
\text { physical activity } \\
\text { through the mass } \\
\text { media }\end{array}$ & $\begin{array}{l}\text { WHO Report } \\
\text { Case studies }\end{array}$ & $\begin{array}{l}\text { Approximately } 7212 \text { tips } \\
\text { were published via social } \\
\text { media, } 2315(32 \%) \text { of } \\
\text { which related to physical } \\
\text { activity }\end{array}$ & $\begin{array}{l}\text { Among the main factors which participated in the } \\
\text { health promotion campaign success is the use of } \\
\text { SMPs such as Instagram and Facebook. }\end{array}$ \\
\hline
\end{tabular}

GCC: Gulf Cooperation Council, KSA: Kingdom of Saudi Arabia, RCT: randomized controlled trial, WHO: World health organization

These followers expressed more interest in receiving more similar content and in using organized systems to convey such information, namely, "Saudi Arabia Networking for Aiding Diabetes (SANAD)" system. Some factors were associated with more intense online "health-related information-seeking behavior", including the female gender, younger people, the marital state, higher revenue, higher level of education, and more prolonged time spent for internet navigation.

Healthcare professional promotion. Authors of 3 studies have successfully used SMPs, "Twitter and YouTube", as cost-efficient and "mass education" platforms to increase the awareness of convenient antibiotic usage in the general population and the medical-related staff of the Gulf countries. Almaiman et $\mathrm{al}^{25}$ revealed that $79 \%$ of the surveyed physicians were seeking online health-related information, and "Twitter" was significantly implicated in improving their medical knowledge and some clinical practice-related issues. Alsobayel et $\mathrm{al}^{32}$ also reported similar findings; as they found SMPs were perceived as being most influential for the development of several competencies as knowledge and problem-solving skill; however, they were perceived as being least helpful in enhancing clinical skills. In a study by Alshakhs et al, ${ }^{44} 20 \%$ of the participants expressed some concerns related to the risk associated with the use of different SMPs, like ethicalor legal-related issues, a risk to the patient's health status, or breach of patient's privacy and confidentiality. However, these participants were willing to use different SMPs for their professional development.

Public health promotion content and SMPs. Several studies analyzed the characteristics and content of some SMPs to define goals for success. Bahkali et $\mathrm{al}^{22}$ reported that the favorable outcome that Twitter achieved brought about by several factors summarized as "defining clear goals, being passionate about the health promotion campaign, being motivated and creative, being knowledgeable about the health promotion area, and developing trust between Twitter users and health-care providers". On the other hand, Mejova et al's ${ }^{16}$ analysis of Instagram posts related to the 
dietary and health activity of the Qatar expats revealed that this population was drastically underrepresented, highlighting the limitation of social media in representing the expat population accurately. Another study by Alhuwail et $\mathrm{a}^{41}$ analyzed the websites of 9 Kuwaiti hospitals. It revealed that these hospitals had a rudimentary online presence which focused mainly on reinforcing services supplied by the hospitals as a type of advertisement rather than engaging the patients or supplying evidence-based-related information. These results highlight gaps in SMP performance that can be addressed to optimize SMPs' use in public health promotion.

Studies providing evidence of better efficacy of health promotion versus standard communication/ health promotion. The ability of different SMP to promote engagement and interaction can complement traditional programs, increasing their ability to promote awareness and change behavior, as evidenced in some reviewed articles. ${ }^{24,31,35,36}$ Additionally, integrating social media networks into other communication programs outside the SMPs will influence the impact of the health promotion activities. ${ }^{45}$

The included studies revealed that different SMPs could enhance women's health promotion level, ${ }^{20,22}$ breast-feeding practices and adherence knowledge, ${ }^{21}$ oral health self-perception and promotion, ${ }^{23,26}$ appropriate antibiotic use, ${ }^{4}$ adherence to physical activity, ${ }^{31}$ road safety awareness, ${ }^{36}$ smoking cessation, ${ }^{38}$ diabetes knowledge, self-efficacy, ${ }^{30,40,43}$ and breast cancer awareness. ${ }^{41}$

Although the predominant study design is a qualitative "cross-sectional" type (76.7\%) using questionnaires or focus groups, with few interventional studies, ${ }^{31,35,40,42,43}$ which proved to be more effective in health promotion than the standard ones, these qualitative studies are still required to provide the basis of fundamental knowledge on which other future studies could be carried out .

Remarks. Public health promotion is a field that can benefit from social media, through web-based and mobile communication social networks. ${ }^{45}$ Different SMPs were widely used to promote health and endorse online health promotion campaigns. These platforms have unique features for exchanging and taking part in open-access information, supplying a channel for dynamic conversations, and allowing users to follow issues of their interest. ${ }^{4}$ Social media platforms have been employed to increase awareness of DM, ${ }^{3}$ obesity, ${ }^{46}$ non-communicable diseases, ${ }^{47}$ sexual health, ${ }^{6}$ and cancers $^{48}$ among others. Besides, they can provide support for "community-based" lifestyle interventions for some people with special conditions like those with mental disorders. ${ }^{49}$

The present review highlights the literature about the current use of different SMPs in public health-related issues within the GCC countries. The findings support that the SMPs application in public health-related research and practice is still in the maturation stage; no articles were found before 2013 , and 30 related articles were published in the last 6 years in the GCC countries. Most included articles used descriptive approaches rather than utilization of the SMPs overall potential in terms of multidirectional communication and networking. Of the 30 articles, most were descriptive research articles, whereas only 5 studies included an interventional approach. ${ }^{31,35,40,42,43}$ This indicates that using different SMPs for health interventions in the GCC countries is not yet a popular approach in public health practice and remains mostly in the descriptive phase of research. More research attempts to specify whether SMPs have an effect on their own or whether the observed outcomes are due to the "non-social media" components or the overall intervention would be important as highlighted by Hamm et al..$^{50}$ Furthermore, a more in-depth analysis of the way the interventions are conducted through different SMPs and the extent to which these interventions are implemented will take part in better understanding of social media use.

Analysis of the country of origin of the studies indicated that the majority of research on the use of SMPs for public health promotion in the GCC countries originated in KSA. The latter country is a fertile one for this sort of research because $75 \%$ of the total Saudi population are "active social media users" in 2017. Approximately 52\% were reported to be active on "Twitter", and 66\% were active on "Facebook".51 These figures reflect the widespread use of SMPs and their potential use in future social media-based public health promotion interventions. Additionally, from a research point of view, the mass population is easily accessible as stated by AlShahrani et al. ${ }^{23}$

By screening the SMPs used in the included studies, "Twitter" was the most common SMP applied in 14 of the 30 articles (46.7\%), and followed by "WhatsApp", which appeared in 7 of the 30 articles (23.3\%). Interestingly, this finding is in line with Reyaee and Ahmed's analysis of the growth pattern of SMPs use in the Gulf countries. 52 They reported that "Twitter" was becoming popular among social media users after "Facebook" in almost all GCC countries.

Although few studies included multiple SMPs or highlighted the importance of combining SMPs with other relatively unprecedented kinds of communication, 
such as messaging or email, $4,33,34,38$ most of the included studies relied on a single SMP. This trend accords with the earlier observations reported by some review articles and meta-analyses that assess the social media use for public health promotion. ${ }^{53-55}$

This work is the first to summarize the role of different SMP in public health promotion in the GCC region. The findings observed in the current study are in agreement with those reported by other studies. For example, Sinnenberg et $\mathrm{a}^{55}$ showed that "Twitter" is supported by multiple organizations that participate in its growth and may have several public health implications. Moorhead et $\mathrm{al}^{12}$ concluded that although SMP is a powerful tool for public health promotion, shared data need to be monitored, and users' privacy should be maintained. Similar concerns were raised by Taggart et al. ${ }^{56}$

Study limitations. Given the relatively new emerging concept of social media with a constantly changing nature, there is no "universal definition," adding difficulty to the strategy of establishing study eligibility and keeping the work updated since new reports are in a steady state of influx. Subjective bias could be unintended and included. The lack of quality, rigor, or validity analyses of the studies was evident. No quantitative statistical analysis could be executed due to the limited number of eligible articles all over the GCC region except for Saudi Arabia and the reported study-design heterogeneity in the retrieved literature. Evaluation of effectiveness in the short and long run using a variety of methodologies, as suggested by Moorhead et $\mathrm{al}^{12}$ is needed, and further evidence synthesis on specific issues, clinical areas, and GCC populations can provide more details.

In conclusion, SMPs have been used for public health promotion for a range of purposes and medical conditions. Moreover, they could improve the professional development of health-care personnel, and their large-scale deployment is highly supported. However, health-care personnel expressed concerns about the quality of disseminated data on these platforms and recommended monitoring data quality.

Social media research has markedly improved in the past decade due to better empirical research and publication of higher quality studies. However, special attention should be directed to populations who are medically underserved and have no or limited access to health-care facilities as potential SMP-targeted groups, among others.

Future SMP-related research is required to cover more countries in the GCC, to carry out more intervention studies, and to include more systematic analysis of the feeds shared between social media users and health-care practitioners.

Acknowledgment. The author would like to thank Editage (www.editage.com) for English language editing for the present article.

\section{References}

1. Statista. Number of social media users worldwide from 2010 to 2021 (in billions). [Update: 2020; Accessed 2018 October 1) Available from: https://www.statista.com/statistics/278414/ number-of-worldwide-social-network-users/

2. Lister C, Royne M, Payne H, Cannon B, Hanson C, Barnes M. The laugh model: reframing and rebranding public health through social media. Am J Public Health 2015; 105 : 2245-2251.

3. Gabarron E, Bradway M, Fernandez-Luque L, et al. Social media for health promotion in diabetes: study protocol for a participatory public health intervention design. BMC Health Serv Res 2018; 18: 414.

4. Zowawi HM, Abedalthagafi M, Mar FA, Almalki T, Kutbi AH, Harris-Brown T, et al. The potential role of social media platforms in community awareness of antibiotic use in the Gulf Cooperation Council States: luxury or necessity? J Med Internet Res 2015; 17: e233.

5. George KS, Roberts CB, Beasley S, Fox M, Rashied-Henry K. Our health is in our hands: a social marketing campaign to combat obesity and diabetes. Am J Health Promot 2016; 30: 283-286.

6. Gabarron E and Wynn R. Use of social media for sexual health promotion: a scoping review. Glob Health Action 2016; 9: 32193.

7. Hudnut-Beumler J, Po'e E, Barkin S. The use of social Media for Health Promotion in Hispanic populations: a scoping systematic review. JMIR Public Health Surveill 2016; 2: e32.

8. World Population Review. GCC Countries 2020. [Update 2019 October 24; Accessed 2020 February 3]. Available from: https://worldpopulationreview.com/country-rankings/gcccountries

9. Saudi Vision 2030. Our Commitments. [Update 2020; Accessed 2020 February 7]. Available from: https://vision2030. gov.sa/en/commitments

10. Menon M, George B. Social media use for patient empowerment in the Gulf Cooperation Council region. Clinical eHealth 2018; 1: 21-27.

11. Chou WS, Prestin A, Lyons C, Wen K. Web 2.0 for health promotion: Reviewing the current evidence. Am J Public Health 2013; 103: e9-e18.

12. Moorhead SA, Hazlett DE, Harrison L, Carroll JK, Irwin A, Hoving C. A new dimension of health care: Systematic Review of the uses, benefits, and limitations of social media for health communication. J Med Internet Res 2013; 15: e85.

13. Fahy E, Hardikar R, Fox A, Mackay S. Quality of patient health information on the Internet: reviewing a complex and evolving landscape. Australas Med J 2014; 7: 24-28.

14. Giustini D, Ali SM, Fraser M, Kamel Boulos MN. Effective uses of social media in public health and medicine: a systematic review of systematic reviews. Online J Public Health Inform 2018; 10: e215. 
15. Sumayyia MD, Al-Madaney MM, Almousawi FH. Health information on social media. Perceptions, attitudes, and practices of patients and their companions. Saudi Med J 2019; 40: 1294-1298.

16. Mejova Y, Haddadi H, Abbar S, A Ghahghaei, Weber I. Dietary habits of an expat nation: Case of Qatar. Proc Int Conf Healthcare Informat (ICHI) 2015; 57-62.

17. World Health Organization. The promotion of physical activity through the mass media, Bahrain. [cited 2018 October 20]. Available from: http://www.emro.who.int/health-education/ physical-activity-case-studies/the-promotion-of-physicalactivity-through-the-mass-media-bahrain.html

18. Alanzi TM, Istepanian RSH, Philip N, Sungoor A. A study on perception of managing diabetes mellitus through social networking in the Kingdom of Saudi Arabia. In: Roa Romero L, editors. XIII Mediterranean Conference on Medical and Biological Engineering and Computing 2013. Seville (Spain): MEDICON; 2013. p. 25-28.

19. Bahkali S, Almaiman A, Alsaleh M, Elmetwally A, Househ M. Web-based Health Educational Program in Saudi Arabia. Stud Health Technol Inform 2014; 202: 63-66.

20. Bahkali S, Almaiman A, Bahkali A, Almaiman S, Househ M, Alsurimi K. The Role of Social Media in Promoting Women's Health Education in Saudi Arabia. Stud Health Technol Inform 2015; 213: 259-262.

21. Bahkali S, Alkharjy N, Alowairdy M, Househ M, Da'ar O, Alsurimi K. A Social Media Campaign to Promote Breastfeeding among Saudi Women: A Web-based Survey Study. Stud Health Technol Inform 2015; 213: 247-250.

22. Bahkali S, Almaiman A, Altassan N, Almaiman S, Househ M, Alsurimi K. Exploring the role of Twitter in promoting women's health in the Arab world: Lessons Learned. Stud Health Technol Inform 2015; 213: 251-254.

23. AlShahrani I, Tikare S, Togoo RA, AlAsere YH, AlAsmari AA. Self-perception of personal oral health in Saudi population: a social media approach. East Mediterr Health J 2015; 21 : 342-348.

24. Jamal A, Khan SA, AlHumud A, et al. Association of Online Health Information-Seeking behavior and self-care activities among type 2 diabetic patients in Saudi Arabia. J Med Internet Res 2015; 17: e196.

25. Almaiman S, Bahkali S, Al Farhan A. The prevalence of using social media among healthcare professionals in Saudi Arabia: A pilot study. Stud Health Technol Inform 2015; 213: 263-266.

26. Almaiman S, Bahkali S, Alabdulatif N, Bahkaly A, Al-Surimi K, Househ M. Promoting Oral Health Using Social Media Platforms: Seeking Arabic Online Oral Health Related Information (OHRI). Stud Health Technol Inform 2016; 226: 283-286.

27. AlQarni ZA, Yunus F and Househ MS. Health information sharing on Facebook: An exploratory study on diabetes mellitus. J Infect Public Health 2016; 9: 708-712.

28. Hajjar WM, Bin Abdulqader SA, Aldayel SS. Knowledge, attitudes, and beliefs toward organ donation among social media users. Transplant Proc 2016; 48: 2418-2422.

29. Bahkali S, Alfurih S, Aldremly M, Alzayyat M, Alsurimi K, Househ M. The prevalence of internet and social media based medication information seeking behavior in Saudi Arabia. Stud Health Technol Inform 2016; 226: 275-278.

30. Alanzi T, Istepanian R, Philip N. Design and usability evaluation of social mobile diabetes management system in the Gulf Region. JMIR Res Protoc 2016; 5: e93.
31. Al-Eisa E, Al-Rushud A, Alghadir A, Anwer S, Al-Harbi, Al-Sughaier NB, et al. Effect of motivation by "Instagram" on adherence to physical activity among female college students. BioMed Research International 2016; 2016: 1546013.

32. Alsobayel H. Use of social media for professional development by health care professionals: A cross-sectional web-based survey. JMIR Med Educ 2016; 2: e15.

33. Alshammari AS, Alshammari HS. Use of social media and other electronic media in health education and health promotion (Pilot Study). Egyptian Journal of Hospital Medicine 2017; 69: 2658-2662.

34. Iftikhar R, Abaalkhail. Health-seeking influence reflected by online health-related messages received on social media: Crosssectional survey. J Med Internet Res 2017; 19: e382.

35. Hemdi A, Daley D. The effectiveness of a psychoeducation intervention delivered via WhatsApp for mothers of children with autism spectrum disorder (ASD) in the Kingdom of Saudi Arabia: A randomized controlled trial. Child Care Health Dev 2017; 43: 933-941.

36. Albalawi YA, Sixsmith J. Exploring the diffusion of tweets designed to raise the road safety agenda in Saudi Arabia. Glob Health Promot 2017; 24: 5-13.

37. Fernandez-Luque L, Singh M, Ofli F, Mejova YA, Weber I, Aupetit M, et al. Implementing $360^{\circ}$ Quantified Self for childhood obesity: feasibility study and experiences from a weight loss camp in Qatar. BMC Med Inform Decis Mak 2017; 17: 37.

38. Onezi HA, Khalifa M, El-Metwally A, Househ M. The impact of social media-based support groups on smoking relapse prevention in Saudi Arabia. Comput Methods Programs Biomed 2018; 159: 135-143.

39. Hassounah MM, AlOwaini HS, Diab CN, Khamis NN. YouTube videos teaching Arabic speaking population how to perform cardiopulmonary resuscitation: The gap between the need and quality. Resuscitation 2018; 131: e13-e14.

40. Alanzi T, Bah S, Alzahrani S, Alshammari S, Almunsef F. Evaluation of a mobile social networking application for improving diabetes type 2 knowledge: an intervention study using WhatsApp. J Comp Eff Res 2018; 7: 891-899.

41. Alhuwail D, AlMeraj Z, Boujarwah F. Evaluating hospital websites in Kuwait to improve consumer engagement and access to health information: a cross-sectional analytical study. BMC Med Inform Decis Mak 2018; 18: 82.

42. Alanzi TM, Alobrah A, Alhumaidi R, Aloraifi S. Evaluation of the SnapChat mobile social networking application for breast cancer awareness among Saudi students in the Dammam Region of the Kingdom of Saudi Arabia. Breast Cancer (Dove Med Press) 2018; 10: 113-119.

43. Alanzi T, Alanazi NR, Istepanian R, Philip N. Evaluation of the effectiveness of mobile diabetes management system with social networking and cognitive behavioural therapy (CBT) for T2D. Mhealth 2018; 4: 35.

44. Alshakhs F, Alanzi T. The evolving role of social media in health-care delivery: measuring the perception of health-care professionals in Eastern Saudi Arabia. J Multidiscip Healthc 2018; 11: 473-479.

45. Centers for Disease Control and Prevention. The health communicator's social media toolkit. Chicago: Electronic Media Branch, Division of News and Electronic Media, Office of the Associate Director of Communication at the Centers for Disease Control and Prevention. [cited 2011]. Available from: https://www.cdc.gov/socialmedia/tools/guidelines/pdf/ socialmediatoolkit_bm.pdf 
46. Jane M, Hagger M, Foster J, Ho S, Pal S. Social media for health promotion and weight management: a critical debate. BMC Public Health 2018; 18: 932.

47. Knight E, Werstine RJ, Rasmussen-Pennington DM, Fitzsimmons D, Petrella RJ. Physical therapy 2.0: leveraging social media to engage patients in rehabilitation and health promotion. Phys Ther 2015; 95: 389-396.

48. Sarkar U, Le GM, Lyles CR, Ramo D, Linos E, BibbinsDomingo K. Using social media to target cancer prevention in young adults: Viewpoint. J Med Internet Res 2018; 20: e203.

49. Naslund JA, Aschbrenner KA, Marsch LA, McHugo GJ, Bartels SJ. Facebook for supporting a lifestyle intervention for people with major depressive disorder, bipolar disorder, and schizophrenia: An Exploratory study. Psychiatr Q 2018; 89: 81-94.

50. Penetration of leading social networks in Saudi Arabia as of 3rd quarter. [cited 2017, Accessed 2019 January 27]. Available from: https://www.statista.com/statistics/284451/saudi-arabiasocial-network-penetration/

51. Reyaee S, Ahmed A. Growth Pattern of Social Media Usage in Arab Gulf States: An Analytical Study. Social Networking 2015; 4: 23-32.
52. Capurro D, Cole K, Echavarría MI, Joe J, Neogi T, Turner AM. The use of social networking sites for public health practice and research: a systematic review. J Med Internet Res 2014; 16: e79.

53. Williams G, Hamm MP, Shulhan J, Vandermeer B, Hartling L. Social media interventions for diet and exercise behaviours: a systematic review and meta-analysis of randomised controlled trials. BMJ Open 2014; 4: e003926.

54. Abroms LC, Schiavo R, Lefebvre C. New media cases in cases in public health communication and marketing: the promise and the potential. Cases in Public Health Communication and Marketing 2008; 2: 3-9.

55. Sinnenberg L, Buttenheim AM, Padrez K, Mancheno C, Ungar L, Merchant RM. Twitter as a tool for health research: A systematic review. Am J Public Health 2017; 107: e1-e8.

56. Taggart T, Grewe ME, Conserve DF, Gliwa C, Roman Isler M. Social Media and HIV: A Systematic Review of Uses of Social Media in HIV Communication. J Med Internet Res 2015; 17 : e248. 